\title{
Research on the Impact of Infrastructure Construction on Tourism Industry: Evidence from the "Wuhan-Guangzhou High-Speed Rail”
}

\author{
Min Yu \\ School of Economics, Jinan University, Guangzhou, China \\ Email: 1240534417@qq.com
}

Received 2 January 2015; accepted 25 January 2016; published 29 January 2016

Copyright (C) 2016 by author and Scientific Research Publishing Inc. This work is licensed under the Creative Commons Attribution International License (CC BY). http://creativecommons.org/licenses/by/4.0/

\begin{abstract}
The "Wuhan-Guangzhou High-Speed Rail" opened on December 26, 2009, which could be regarded as a quasi-natural experiment that improved the quality of transportation infrastructure. With the cities having the stops of "Wuhan-Guangzhou High-Speed Rail" as the treatment group, other cities in the same provinces but without any high speed railway stops as the control group, this paper constructs the panel data from 2005 to 2013 and uses Difference in Differences method to investigate the impact of the opening of "Wuhan-Guangzhou High-Speed Rail" on the tourism economy. We find that tourism revenue in cities from treatment group increased by 13.734 billion to 22.482 billion yuan, and the total number of domestic tourist arrivals increased by 12.9814 million to 16.2512 million people. The conclusion proves that the construction of transportation infrastructure promotes the tourism industry, making up for the insufficient empirical research on the development of tourism.
\end{abstract}

\section{Keywords}

High-Speed Railway, Tourism Economy, DID (Difference in Differences)

\section{Introduction}

The development of tourism industry is closely related to the construction of transportation infrastructure. Generally speaking, the tourists choose different forms of tourism traffic according to local conditions for different travel needs, such as: road, rail, aviation, water, etc. With the rapid development of China's railway construction, 
high-speed railway (abbreviation: "high-speed rail") tourism as a new form of tourism, with a relatively low price and efficient speed, has won the favor of the majority of passengers. With the increase of the number of high-speed railway in China and the formation of network, the new round of competition of China's high speed railway has led to the integration of city tourism center, which has an important impact on the development of tourism industry [1]. For example, the opening of the "Wuhan-Guangzhou high-speed rail" on December 26, 2009, shortened the travel time between the cities along the line. It is generally believed that this has promoted the development of tourism industry in Guangdong, Hunan and Hubei. However, what is the quantitative effect of economic pull? At present, there is no literature about related research. In this paper, we take the "Wuhan-Guangzhou high-speed railway" as an example, use the method of DID (Difference in differences, DID), and analyze the impact of the opening of the high-speed rail on tourism revenue and the number of tourists, so as to promote the development of tourism policy arrangements to provide empirical evidence.

\section{Review of Literature}

A considerable part of the research results show that infrastructure has a positive effect on economic development. Donaldson [2] researched on the impact of the railway network in the colonial period of India, and found that the railway had reduced trade costs and regional price differences, thus improved international and regional trade and income levels. Cascetta et al. [3] found that the high-speed rail between Rome and Naples in Italy contributed to a large number of new travel demand. Ye and Wang [4] examined the relationship between the development of transportation industry and regional economic growth by using the spatial panel model. And the results show that the influence of rail transport on economic growth is greater than that of road transport. Qu and $\mathrm{Li}$ [5] found that there were large regional differences in the economic role of transportation infrastructure, the role of transport infrastructure in the eastern region was not obvious, and there was still a bottleneck restricting the development of the economy in the western region, while in the middle region, only the role of goods transport was obvious.

On the whole, the economic function of "high-speed railway" has been discussed, while the empirical analysis of the "Wuhan-Guangzhou high-speed railway" is still relatively rare. This paper takes "Wuhan-Guangzhou high-speed railway" as an example and bases on the empirical analysis of economic impact of the transportation infrastructure, in order to obtain empirical evidence to fill the gaps in the research area.

\section{Research Program and Data}

DID method has been widely used in research areas of policy effects. By selecting comparable control group, the method can partly overcome the endogenous problem. With the basic regression equation of the economic effects of high-speed rail, DID was analyzed and can be explained in mathematical form as follows:

$$
y_{i t}=\alpha+\beta d u_{i} \times d t_{t}+\lambda d u_{i}+\delta d t_{t}+\gamma X+\varepsilon_{i t}
$$

In Equation (1), the subscript $i$ and $t$ are the cross-sectional area and time respectively, $y$ and $\varepsilon$ are the performance of the tourism industry, and disturbance term respectively. The indexes of the performance of the tourism industry include total tourism revenue (TR) and domestic tourism (DT). $d_{u}$ is a dummy variable which is used to distinguish groups, for treatment group $d_{u}=1$, for control group, $d_{u}=0$. In other words, If the high-speed rail goes through the city, the $d_{u}$ is selected as 1 otherwise it is $0 . d_{t}$ represents the time dummy variable, before the opening of the Wuhan-Guangzhou high-speed rail, $d_{t}=0$, otherwise, $d_{t}=1$. The Wuhan-Guangzhou high-speed rail was officially run on 26 December, 2009. Considering that the annual date is used in this article, the year 2010 is chosen to be a cut-off point. Before 2010, $d_{t}=0$, after 2010, $d_{t}=1$. Therefore, all samples are divided into 4 groups with two dimensions, which means that the samples include treatment group and control group before and after the opening of Wuhan Guangzhou high-speed railway. In addition, we use the estimated coefficient of the product terms of two dummy variables $\beta$ in the regression equation which help to measures the change of the performance of tourism brought by "Wuhan-Guangzhou high-speed rail” with respect to the performance of the places without any high-speed rail.

At the same time, we need to consider the other factors that affect economic growth as a control variable to which further overcome the endogeneity. In Equation (1), $X$ is the control variable vector. The other indicators were selected as following:

1) Rgdp: regional gross domestic product (Unit: yuan), is the level of regional economic development. This 
factor reflects the level of local economic development. The levels of economic development affect the development of tourism, on the one hand, change the construction of tourist facilities, on the other hand, change the consumption demand of residents in tourism.

2) Health: the development level of human capital. This indicator is measured by the number of beds in hospitals and health institutions. Because the reasons for the lack of direct metrics, this variable is used to control the health dimension of human capital. Level of human capital development is an important part of the development of service industry, tourism as an important part of the service sector, the level of human capital has a greater effect on the quality of the tourism industry.

3) Structure: regional industrial structure level. The tertiary industry output value/GDP, measured in percentage (\%). Tourism belongs to the service sector, and the development of service industry need the support of other industries, thus, the industrial structure can explain the maturity and potential of service development.

4) Population: density of population. (Unit: people $/ \mathrm{km}^{2}$.) The indicator reflects the degree of aggregation of the city's population. Agglomeration of the population is a measure of market size, meanwhile there is a certain impact on the popularity of tourism resources and configuration capabilities.

5) Year: Year fixed effects.We use the annual fixed effects to control the time dimension of an annual trend of macroeconomic development time and avoid the overestimate of estimated coefficients $\beta$.

For the selection of the treatment and control groups, as the Wuhan-Guangzhou high-speed rail cross ten prefecture-level cities, these ten cities are selected as the treatment group which are Wuhan, Xianning, Yueyang, Changsha, Zhuzhou, Hengyang, Chenzhou, Shaoguan, Qingyuan and Guangzhou. Based on the assumptions that diference between samples from adjacent space is relatively small,so we choose 18 cities in Hunan, Hubei and Guangdong provinces that have no high-speed rail till November 2014 as a control group. They are Xiangtan, Yiyang, Changde, Shaoyang, Zhangjiajie, Loudi, Jingmen, Huanggang, Shantou, Foshan, Zhanjiang, Maoming, Zhaoqing, Meizhou, Heyuan, Yangjiang, Chaozhou, Jieyang, as shown in Table 1.

This paper analyzes data from each city's "Statistics Communique on National Economy and Social Development”, "China City Statistical Yearbook" and "China Statistical Yearbook for Regional Economy” in the year of 2005-2013. Table 2 shows the data descriptive statistics.

\section{Results and Discussion}

We need to do further analysis by DID. The results are shown in Table 3.

Table 1. The list of treatment group and control group.

\begin{tabular}{cc}
\hline Treatment group & Control Group \\
\hline $\begin{array}{c}\text { Wuhan, Xianning, Yueyang, Changsha, } \\
\text { Zhuzhou, Hengyang, Chenzhou, Shaoguan, } \\
\text { Qingyuan, Guangzhou }\end{array}$ & $\begin{array}{c}\text { Xiangtan, Yiyang, Changde, Shaoyang, Zhangjiajie, Loudi, Jingmen, } \\
\text { Huanggang, Shantou, Foshan, Zhanjiang, Maoming, Zhaoqing, } \\
\text { Meizhou, Heyuan, Yangjiang, Chaozhou, Jieyang }\end{array}$ \\
\hline
\end{tabular}

Table 2. Descriptive statistics.

\begin{tabular}{|c|c|c|c|c|c|c|}
\hline Variables & Indicators & Obs. & Mean & Std. & Min. & Max. \\
\hline $\begin{array}{c}\text { Total tourism revenue } \\
\text { (Unit: a hundred million RMB) }\end{array}$ & $T R$ & 252 & 157.18 & 293.77 & 8.50 & 2202.39 \\
\hline $\begin{array}{l}\text { Domestic tourist arrivals } \\
\text { (Unit: ten thousand people) }\end{array}$ & $D T$ & 252 & 1318.51 & 1913.83 & 118 & $17,022.11$ \\
\hline $\begin{array}{l}\text { Level of regional economic } \\
\text { development (Unit: yuan) }\end{array}$ & $R g d p$ & 252 & $27,036.17$ & $21,637.31$ & 4799 & 119,695 \\
\hline $\begin{array}{l}\text { Number of beds in hospitals and } \\
\text { health institutions }\end{array}$ & Health & 252 & $14,986.38$ & $12,253.25$ & 1800 & 70,649 \\
\hline $\begin{array}{c}\text { Regional Industry Structure } \\
\text { Level (Unit: \%) }\end{array}$ & Structure & 252 & 38.61 & 7.69 & 27.23 & 64.62 \\
\hline $\begin{array}{l}\text { Population density } \\
\text { (Unit: people/sq km) }\end{array}$ & Population & 252 & 559.69 & 466.99 & 168.26 & 2616.23 \\
\hline
\end{tabular}


Table 3. DID regression results.

\begin{tabular}{|c|c|c|c|c|}
\hline & \multicolumn{2}{|c|}{ Total tourism revenue (TR) } & \multicolumn{2}{|c|}{ Domestic tourist arrivals (DT) } \\
\hline & (1) & (2) & (3) & (4) \\
\hline$d u_{i} \times d t_{t}$ & $\begin{array}{c}224.82^{* *} \\
(2.10)\end{array}$ & $\begin{array}{c}137.34^{*} \\
(1.86)\end{array}$ & $\begin{array}{c}1625.12^{* *} \\
(2.19)\end{array}$ & $\begin{array}{c}1298.14^{* *} \\
(2.21)\end{array}$ \\
\hline$d_{t}$ & $\begin{array}{l}-51.25 \\
(-1.53)\end{array}$ & $\begin{array}{l}-45.58^{*} \\
(-1.96)\end{array}$ & $\begin{array}{l}-400.48 \\
(-1.65)\end{array}$ & $\begin{array}{c}-416.76^{*} \\
(-1.89)\end{array}$ \\
\hline$d_{u}$ & $\begin{array}{l}125.35 \\
(1.66)\end{array}$ & $\begin{array}{l}-54.77 \\
(-1.16)\end{array}$ & $\begin{array}{c}958.65^{* *} \\
(2.39)\end{array}$ & $\begin{array}{l}-36.03 \\
(-0.13)\end{array}$ \\
\hline Rgdp & & $\begin{array}{c}0.004^{* *} \\
(2.10)\end{array}$ & & $\begin{array}{l}-0.006 \\
(-0.42)\end{array}$ \\
\hline Health & & $\begin{array}{c}0.012^{* * *} \\
(4.77)\end{array}$ & & $\begin{array}{l}0.11^{* *} \\
(2.32)\end{array}$ \\
\hline Structure & & $\begin{array}{l}8.38^{* * * *} \\
(4.25)\end{array}$ & & $\begin{array}{c}1.54 \\
(0.06)\end{array}$ \\
\hline Population & & $\begin{array}{l}0.006 \\
(0.32)\end{array}$ & & $\begin{array}{l}-0.015 \\
(-0.11)\end{array}$ \\
\hline Year & $\begin{array}{l}27.16^{* * *} \\
(3.62)\end{array}$ & $\begin{array}{c}1.89 \\
(0.31)\end{array}$ & $\begin{array}{c}221.22^{* * *} \\
(4.08)\end{array}$ & $\begin{array}{c}133.88^{* *} \\
(3.06)\end{array}$ \\
\hline Constant & $\begin{array}{c}-54,472.92^{* * *} \\
(-3.62)\end{array}$ & $\begin{array}{c}-4240.76 \\
(-0.35)\end{array}$ & $\begin{array}{c}-443,534.4^{* * *} \\
(-4.07)\end{array}$ & $\begin{array}{c}-269,123.5^{* *} \\
(-3.07)\end{array}$ \\
\hline$R^{2}$ & 0.2489 & 0.8511 & 0.3347 & 0.6184 \\
\hline Observations & & & 252 & \\
\hline Event Year & & & 2010 & \\
\hline Sample period & & & 2005-2013 & \\
\hline
\end{tabular}

Note: The values in parentheses correspond to $t$ test. ${ }^{*},{ }^{* *}$ and ${ }^{* * *}$ represent the significance of $10 \%, 5 \%$ and $1 \%$ respectively. The results are based on Stata regression and robust standard estimates.

According to the regression results in Table 3 (1) and (2), we can see the impact of high-speed rail to total tourism revenue is positive, $\beta=224.82$, and on $5 \%$ significance level significantly. After adding various control variables, the coefficient is 137.34 , and on $10 \%$ significance level significantly. That means that the running of the Wuhan-Guangzhou high-speed railway have promoted the total tourism revenue along the site of the city, with respect to the non-urban sites, the average increase per year is about 13.7 to 22.5 Billion Yuan. In column (3) and (4), we use domestic tourist arrivals to replace total tourism revenue as the explanatory variable, all other variables are unchanged, then do DID regression. (3) column shows $\beta=1625.12$, significance level is $5 \%$. After adding control variables, (4) column shows $\beta=1298.14$, significance level is still $5 \%$. It shows that the domestic tourist arrivals of the city along the high-speed rail increase by 12.98 to 16.25 million people per year. These conclusions suggest that transportation infrastructure can improve the economic performance of the tourism industry.

\section{Robustness Test}

The analysis in the previous part shows that the running of the "Wuhan-Guangzhou high-speed railway" has promoted the development of tourism in the cities along the line. In order to confirm the robustness of this conclusion, we need to carry out Placebo test. Placebo test is commonly used as a robust test method, such as Abadie and Gardeazabal [6], Della Vigna and Kaplan [7], Waldinger [8], La Ferrara et al. [9]. The basic idea of Placebo test is that, according to some other economic laws which are likely to affect the results of the research, we construct false treatment group and the control group, do DID regression and observe whether the coefficient is significant or not; if it is significant, then effect of the event in original treatment group may be accidental or random, on the contrary, this possibility can be reduced considerably. This section, we will set up three false 
control groups, the regression results confirm the robustness of the previous conclusions.

Specifically, due to the cities from different provinces belong to different administrative regions, these cities are affected by different local economic policy, and therefore there are differences in the change of economic performance. Then, the resulting above regarding the impact of "Wuhan-Guangzhou high-speed rail" on tourism, in order to exclude the possibility that the different administrative regions are affected by different macroeconomic factors caused the wrong results, we need to do Placebo test. Within the scope of the original sample, we choose cities in Guangdong Province, Hunan and Hubei Province as the treatment groups, with cities in other provinces as a control group, to carry out a comparative analysis of the same regression. Three false control groups are shown in Table 4.

In Table 5, column (1) and (2) are the results of the analysis of the treatment group based in Guangdong,

Table 4. Robustness test: list of false treatment groups and control groups.

\begin{tabular}{|c|c|c|}
\hline & Treatment groups & Control groups \\
\hline 1 & $\begin{array}{l}\text { Shaoguan, Qingyuan, Guangzhou, Shantou, Foshan, } \\
\text { Maoming, Zhaoqing, Meizhou, Heyuan, Yangjiang, } \\
\text { Chaozhou, Zhanjiang, Jieyang }\end{array}$ & $\begin{array}{c}\text { Wuhan and Xianning, Yueyang, Chenzhou, Xiangtan, Yiyang, } \\
\text { Jingmen, Huanggang, Zhangjiajie, Changsha, Zhuzhou, Changde, } \\
\text { Shaoyang, Hengyang, Loudi }\end{array}$ \\
\hline 2 & $\begin{array}{c}\text { Hengyang, Chenzhou, Yueyang, Changsha, Zhuzhou, } \\
\text { Xiangtan, } \\
\text { Shaoyang, Yiyang, Zhangjiajie, Changde, Loudi }\end{array}$ & $\begin{array}{c}\text { Wuhan and Xianning, Zhaoqing, Shaoguan, Qingyuan, Guangzhou, } \\
\text { Jingmen, Huanggang, Jieyang, Shantou, Yangjiang, Chaozhou, } \\
\text { Foshan, Meizhou, Heyuan, Zhanjiang, Maoming }\end{array}$ \\
\hline 3 & WuHan, Xianning, Jingmen, Huanggang & $\begin{array}{l}\text { Changsha, Zhuzhou, Xiangtan, Zhaoqing, Jieyang, Zhanjiang, } \\
\text { Shaoguan, Qingyuan, Guangzhou and Hengyang, Chenzhou, } \\
\text { Yueyang, Changde, Loudi, Maoming, Shantou, Yangjiang, Chaozhou, } \\
\text { Foshan, Meizhou, Heyuan, Shaoyang, Yiyang, Zhangjiajie }\end{array}$ \\
\hline
\end{tabular}

Table 5. The results of robustness test.

\begin{tabular}{|c|c|c|c|c|c|c|}
\hline & $\mathrm{TR}$ & $\mathrm{DT}$ & TR & DT & TR & $\mathrm{DT}$ \\
\hline & (1) & (2) & (3) & (4) & (5) & (6) \\
\hline$d u_{i} \times d t_{t}$ & $\begin{array}{c}-1.84 \\
(-0.03)\end{array}$ & $\begin{array}{c}-1079.02^{* *} \\
(-2.60)\end{array}$ & $\begin{array}{l}-47.52 \\
(-0.88)\end{array}$ & $\begin{array}{l}147.01 \\
(0.30)\end{array}$ & $\begin{array}{l}99.05 \\
(0.73)\end{array}$ & $\begin{array}{c}1769.54 \\
(1.19)\end{array}$ \\
\hline$d_{t}$ & $\begin{array}{l}11.25 \\
(0.38)\end{array}$ & $\begin{array}{c}597.42^{* *} \\
(2.26)\end{array}$ & $\begin{array}{l}29.01 \\
(1.00)\end{array}$ & $\begin{array}{l}39.97 \\
(0.16)\end{array}$ & $\begin{array}{c}-3.9 \\
(-0.23)\end{array}$ & $\begin{array}{c}-152.66 \\
(-0.82)\end{array}$ \\
\hline$d_{u}$ & $\begin{array}{l}43.87 \\
(1.43)\end{array}$ & $\begin{array}{c}-369.94 \\
(-1.64)\end{array}$ & $\begin{array}{l}-33.13 \\
(-1.09)\end{array}$ & $\begin{array}{l}50.79 \\
(0.23)\end{array}$ & $\begin{array}{l}-16.25 \\
(-0.25)\end{array}$ & $\begin{array}{c}377.18^{*} \\
(2.02)\end{array}$ \\
\hline $\operatorname{Rgdp}$ & $\begin{array}{l}0.004^{*} \\
(1.78)\end{array}$ & $\begin{array}{l}0.004 \\
(0.25)\end{array}$ & $\begin{array}{l}0.004^{*} \\
(1.81)\end{array}$ & $\begin{array}{l}-0.005 \\
(-0.28)\end{array}$ & $\begin{array}{c}0.0046^{* *} \\
(2.09)\end{array}$ & $\begin{array}{c}-0.0014 \\
(-0.09)\end{array}$ \\
\hline Health & $\begin{array}{c}0.013^{* * *} \\
(4.57)\end{array}$ & $\begin{array}{l}0.098^{* *} \\
(2.37)\end{array}$ & $\begin{array}{c}0.013^{* * *} \\
(1.81)\end{array}$ & $\begin{array}{l}0.12^{* *} \\
(2.27)\end{array}$ & $\begin{array}{c}0.012^{* * *} \\
(4.14)\end{array}$ & $\begin{array}{c}0.108^{* * *} \\
(3.25)\end{array}$ \\
\hline Structure & $\begin{array}{l}8.10^{* * *} \\
(5.65)\end{array}$ & $\begin{array}{l}12.94 \\
(0.84)\end{array}$ & $\begin{array}{c}8.053^{* * *} \\
(4.72)\end{array}$ & $\begin{array}{c}-1.41 \\
(-0.06)\end{array}$ & $\begin{array}{l}8.85^{* * *} \\
(4.41)\end{array}$ & $\begin{array}{l}0.108 \\
(0.34)\end{array}$ \\
\hline Population & $\begin{array}{l}-0.012 \\
(-0.77)\end{array}$ & $\begin{array}{c}0.13 \\
(0.72)\end{array}$ & $\begin{array}{l}-0.013 \\
(-0.86)\end{array}$ & $\begin{array}{c}-0.15 \\
(-1.13)\end{array}$ & $\begin{array}{c}0.004 \\
(0.26)\end{array}$ & $\begin{array}{l}-0.099 \\
(-0.64)\end{array}$ \\
\hline Year & $\begin{array}{c}0.47 \\
(0.08)\end{array}$ & $\begin{array}{c}103.02^{* *} \\
(2.53)\end{array}$ & $\begin{array}{c}0.38 \\
(0.06)\end{array}$ & $\begin{array}{l}106.3^{* *} \\
(2.36)\end{array}$ & $\begin{array}{c}0.17 \\
(0.03)\end{array}$ & $\begin{array}{c}109.28^{* *} \\
(2.42)\end{array}$ \\
\hline Constant & $\begin{array}{c}-1428.85 \\
(-0.12)\end{array}$ & $\begin{array}{c}-207,664.7^{* *} \\
(-2.55)\end{array}$ & $\begin{array}{c}-1201.37 \\
(-0.10)\end{array}$ & $\begin{array}{c}-213,874.8^{* *} \\
(-2.38)\end{array}$ & $\begin{array}{c}-827.65 \\
(-0.07)\end{array}$ & $\begin{array}{c}-220,155^{* *} \\
(-2.43)\end{array}$ \\
\hline$R^{2}$ & 0.8405 & 0.6480 & 0.8450 & 0.5946 & 0.8408 & 0.6612 \\
\hline Observations & \multicolumn{2}{|c|}{252} & \multicolumn{2}{|c|}{252} & \multicolumn{2}{|c|}{252} \\
\hline $\begin{array}{l}\text { Treatment } \\
\text { Group }\end{array}$ & \multicolumn{2}{|c|}{ Guangdong } & \multicolumn{2}{|c|}{ Hunan } & \multicolumn{2}{|c|}{ Hubei } \\
\hline
\end{tabular}

Note: 2010 is the event time, the sample period is during $2005-2013$. The values in parentheses correspond to $t$ tests. ${ }^{*}{ }^{* *}$, and ${ }^{* * *}$ indicate the significance of $10 \%, 5 \%$ and $1 \%$ respectively. The results are based on the use of Stata regression, and the use of robust correction estimates. 
when domestic tourist arrivals is used as the dependent variable in the regression, the cross-term coefficient is significant, while the total tourism revenue as the independent variable in the regression is not significant. So the administrative factors which influence the role of the tourism industry in the opening period of "WuhanGuangzhou high-speed rail” are not robust. The regression results of the other two division methods, from column (3) to (6), the results show the cross-term $d u_{i} \times d t_{t}$ of the treatment group based in Hunan and Hubei are not significant, which are consistent with the results in column (1) and (2).

Thus, the robustness test results indicate that before and after the opening of the "Wuhan-Guangzhou highspeed rail," the macroeconomic factors related to regional differences in administration did not have a significant impact on the changes along the city's tourism performance, which meant that the conclusion we drew in the previous part was robust.

\section{Conclusions}

The impact of infrastructure construction on economy has been concerned consistently, and the development of the tourism industry is benefited from the improving transport infrastructure. In recent years, the development of high-speed rail construction is very rapid in China, but there is rare empirical analysis of the impact of highspeed rail construction on tourism development. In this paper, we use the "Wuhan-Guangzhou high-speed rail" as an example, and use DID (Difference in Differences) to analyze the impact of high-speed railway on tourism revenues and domestic tourist arrivals. Analysis shows that high-speed rail along the city makes total tourism revenues increase by 13.734 billion to 22.482 billion Yuan, and the total domestic tourist arrivals increase by 12.9814 million to 16.2512 million people. Placebo test proves that the conclusion is robust. The importance of the "tourism economy" has been demonstrated in this article, so the regional tourism administration should plan high-speed rail transport routes based on the docking site in order to improve the accessibility of tourist attractions and the convenience tourist.

In spite of the merits, this paper has some limitations at the same time. For example, the data can be accurated to the county level in order to get more detailed results. However, most of the counties didn't open its statistical data to the public, that's why only the city level data is used in this paper. In my future research, I will try to get some more specific data by emailing to the statistical bureau and try to buy some useful resources.

\section{References}

[1] Wang, X., Huang, S.S., Zou, T.Q. and Yan, H. (2012) Effects of the High Speed Rail Network on China's Regional Tourism Development. Tourism Management Perspectives, 1, 34-38. http://dx.doi.org/10.1016/j.tmp.2011.10.001

[2] Donaldson, D. (2010) Railroads of the Raj: Estimating the Impact of Transportation Infrastructure. NBER Working Paper No. 16487.

[3] Cascetta, E., Papola, A., Pagliara, F. and Marzano, V. (2011) Analysis of Mobility Impacts of the High Speed RomeNaples Rail Link Using Within-Day Dynamic Mode Service Choice Models. Journal of Transport Geography, 19, 635-643. http://dx.doi.org/10.1016/j.jtrangeo.2010.07.001

[4] Ye, C.Y. and Wang, X.J. (2013) Transport Infrastructure and Economic Growth in China-Based on Spatial Econometrics of Panel Data with Provincial Data. Industrial Economics Research, 2, 40-47.

[5] Qu, Ch. and Li, X.M. (2015) Economic Development or Factor Loss: The Study on the Regional Differences of the Economic Role of Transportation Infrastructure. Modern Economic Science, 1, 32-38.

[6] Abadie, A. and Gardeazabal, J. (2003) The Economic Costs of Conflict: A Case Study of the Basque Country. The American Economic Review, 93, 113-132. http://dx.doi.org/10.1257/000282803321455188

[7] DellaVigna, S. and Kaplan, E. (2007) The Fox News Effect: Media Bias and Voting. The Quarterly Journal of Economics, 122, 1187-1234. http://dx.doi.org/10.1162/qjec.122.3.1187

[8] Waldinger, F. (2010) Quality Matters: The Expulsion of Professors and the Consequences for PhD Student Outcomes in Nazi Germany. Journal of Political Economy, 118, 787-831. http://dx.doi.org/10.1086/655976

[9] La Ferrara, E., Chong, A. and Duryea, S. (2012) Soap Operas and Fertility: Evidence of Brazil. American Economic Journal: Applied Economics, 4, 1-31. http://dx.doi.org/10.1257/app.4.4.1 